\title{
The Serum Expression of Selected miRNAs in Pulmonary Sarcoidosis with/without Löfgren's Syndrome
}

\author{
Eva Novosadova, ${ }^{1}$ Alzbeta Chabronova, ${ }^{1}$ Vitezslav Kolek, ${ }^{2}$ \\ Martin Petrek, ${ }^{1,3}$ and Zdenka Navratilova ${ }^{1,3}$ \\ ${ }^{1}$ Laboratory of Immunogenomics, Department of Pathological Physiology, Faculty of Medicine and Dentistry, \\ Palacky University, Olomouc, Czech Republic \\ ${ }^{2}$ Department of Respiratory Medicine and TBC, Palacky University, Olomouc, Czech Republic \\ ${ }^{3}$ Institute of Molecular and Translational Medicine, Faculty of Medicine and Dentistry, Palacky University, Olomouc, Czech Republic
}

Correspondence should be addressed to Martin Petrek; martin.petrek@fnol.cz

and Zdenka Navratilova; zdenkalnavratilova@gmail.com

Received 30 August 2016; Accepted 10 November 2016

Academic Editor: Alex Kleinjan

Copyright @ 2016 Eva Novosadova et al. This is an open access article distributed under the Creative Commons Attribution License, which permits unrestricted use, distribution, and reproduction in any medium, provided the original work is properly cited.

Purpose. Pulmonary sarcoidosis is associated with dysregulated expression of intracellular miRNAs. There is however only little information on extracellular miRNAs and their association with the disease course in sarcoidosis. We therefore assessed serum miRNAs in sarcoidosis classified according to the presence of Löfgren's syndrome (LS) as a hallmark of good prognosis in contrast to more advanced disease course. Methods. RT-PCR was used to assess 35 miRNAs in 13 healthy controls and 24 sarcoidosis patients (12 with X-ray (CXR) stage $\leq 1$ and LS and 12 with insidious onset and CXR stage $\geq 3$ ). Results. Compared to controls, we consistently observed dysregulated expressions of miR-146, miR-16, miR-425-5p, and miR-93-5p in both sarcoidosis groups irrespective of disease course. Specifically, patients without LS had dysregulated expressions of miR-150-5p, miR-1, and miR212 compared to controls. Patients with LS had dysregulated expressions of miR-21-5p and miR-340-5p compared to controls. Bioinformatics predicted consistently "Pathways in cancer" to be modulated by both altered profiles in patients with/without LS. Three miRNAs (miR-21-5p, miR-340-5p, and miR-212-3p) differed between our patients with LS and those without LS; their cumulative effect may modulate "TGF- $\beta$ signalling pathway." Conclusions. Further study should focus on possible applications of serum miRNAs for diagnostics follow-up and for prognosis.

\section{Introduction}

Pulmonary sarcoidosis is an inflammatory granulomatous disease of unknown cause(s) [1]. The course and prognosis of sarcoidosis vary greatly. High rate of spontaneous remissions is known in patients with early disease that present constellation of specific features called Löfgren's syndrome. On the other hand, an insidious onset of the disease without Löfgren's syndrome may be followed by progressive fibrosis [1].

Sarcoidosis progression has not been associated with any particularly specific immunological parameters although sarcoidosis inflammation is generally characterized by elevated production of proteolytic enzymes, cytokines and chemokine ligands/receptors, and other molecules with immune-regulatory functions $[1,2]$. Expression of these proinflammatory factors is modulated by miRNome that composes of numerous small single-stranded (20-24 nucleotides long) noncoding RNAs termed miRNAs (alias microRNAs). They bind to complementary mRNA sequences within target genes whose expression is subsequently regulated through posttranscriptional repression [3]. The regulatory property of miRNAs is generally associated with their cytoplasmic accumulation in a cell [3].

In pulmonary sarcoidosis, the intracellular expression of miRNAs has been investigated in bronchoalveolar cells, peripheral blood mononuclear cells, and the lung tissue [4-6]. In addition, some intracellular miRNAs have been reported to have altered expression during sarcoidosis progression $[4,5]$. 
TABLE 1: Clinical characteristics of our patients with pulmonary sarcoidosis and healthy controls.

\begin{tabular}{|c|c|c|c|}
\hline & \multirow{2}{*}{ Healthy controls $N=13$} & \multicolumn{2}{|c|}{ Sarcoidosis } \\
\hline & & With LS $(\mathrm{CXR} \leq 1) N=12$ & Without LS $(\mathrm{CXR} \geq 3) N=12$ \\
\hline Gender, men/women & $2 / 11$ & $8 / 4$ & $6 / 6$ \\
\hline Mean age (min-max) & $45.6(23-62)$ & $45.5(32-62)$ & $46.6(26-72)$ \\
\hline $\begin{array}{l}\text { Smoking history } \\
\text { (nonsmoker/ex-smoker*/current smoker/NA) }\end{array}$ & $13 / 0 / 0 / 0$ & $9 / 1 / 1 / 1$ & $9 / 2 / 1 / 0$ \\
\hline CXR stage $0 / 1$ & NA & 12 & NA \\
\hline CXR stage $3 / 4$ & NA & NA & $10 / 2$ \\
\hline FEV1 (min-max) $(\%)$ & NA & $106(99-109)$ & $90(59-113)$ \\
\hline FEV1/VC (min-max) (\%) & NA & $81(69-90)$ & $76(74-80)$ \\
\hline Mean DLCO (min-max) (\%) & NA & $101(82-131)$ & $78(46-98)$ \\
\hline Mean DLCO/VA (min-max) (\%) & NA & $90(84-94)$ & $103(95-115)$ \\
\hline
\end{tabular}

NA, not available or not applicable; CXR, chest X-ray; LS, Löfgren's syndrome; DLCO, diffusing capacity of the lung for carbon monoxide; VA, alveolar volume and $*$ a nonsmoker was defined as a never smoker and an ex-smoker was defined as someone who has not been smoking for at least 2 years before serum collection. FEV1, forced expiratory volume in 1 second; VC, vital capacity.

TABLE 2: Bronchoalveolar cellular profile in our patients with pulmonary sarcoidosis.

\begin{tabular}{|c|c|c|}
\hline Sarcoidosis & With LS $(\mathrm{CXR} \leq 1) N=12$ & Without LS $(\mathrm{CXR} \geq 3) N=12$ \\
\hline Cellular profile & Mean $(\min -\max )$ & Mean $(\min -\max )$ \\
\hline Total cell count $10^{6} / \mathrm{mL}$ & $0.85(0.40-1.35)$ & $0.72(0.10-1.40)$ \\
\hline Macrophage absolute count & $0.66(0.28-1.02)$ & $0.58(0.09-1.40)$ \\
\hline Macrophage relative count (\%) & $77.31(57.00-91.10)$ & $76.67(43.00-90.70)$ \\
\hline Lymphocytes absolute count & $0.18(0.06-0.45)$ & $0.14(0.01-0.33)$ \\
\hline Lymphocytes relative count (\%) & $20.58(8.60-41.00)$ & $20.08(8.00-46.00)$ \\
\hline Neutrophils absolute count & $0.01(0.00-0.04)$ & $0.02(0.00-0.05)$ \\
\hline Neutrophils relative count (\%) & $1.68(0.00-8.00)$ & $2.27(0.00-6.00)$ \\
\hline Eosinophils absolute count & $0.00(0.00-0.01)$ & $0.00(0.00-0.02)$ \\
\hline Eosinophils relative count (\%) & $0.43(0.00-2.00)$ & $0.99(0.00-7.00)$ \\
\hline $\mathrm{CD}^{+}$absolute count & $0.56(0.00-1.13)$ & $0.35(0.00-1.06)$ \\
\hline $\mathrm{CD}^{+}$relative count $(\%)$ & $84.62(58.00-94.00)$ & $75.00(36.00-96.00)$ \\
\hline $\mathrm{CD}^{+}$absolute count & $0.26(0.00-0.79)$ & $0.15(0.00-0.67)$ \\
\hline $\mathrm{CD}^{+}$relative count $(\%)$ & $71.69(35.00-90.00)$ & $55.58(29.00-89.00)$ \\
\hline $\mathrm{CD}^{+}$absolute count & $0.06(0.00-0.26)$ & $0.04(0.00-0.19)$ \\
\hline $\mathrm{CD}^{+}$relative count $(\%)$ & $13.08(3.00-31.00)$ & $21.00(4.00-53.00)$ \\
\hline $\mathrm{CD} 9^{+}$absolute count & $0.00(0.00-0.01)$ & $0.00(0.00-0.02)$ \\
\hline $\mathrm{CD} 9^{+}$relative count $(\%)$ & $0.54(0.00-2.00)$ & $1.08(0.00-2.00)$ \\
\hline $\mathrm{CD}^{+} / \mathrm{CD}^{+}$ & $9.45(1.13-30.00)$ & $5.34(0.55-22.25)$ \\
\hline
\end{tabular}

CXR, chest X-ray; LS, Löfgren's syndrome.

Besides their intracellular accumulation, however, miRNAs are known to be present in extracellular fluids [79]. Little information on the extracellular miRNAs only exists in sarcoidosis [7]. In addition, the sparse data should be confirmed with regard to current recommendation for normalisation strategy of extracellular miRNAs $[7,10]$.

We have therefore investigated expression stability of serum miRNAs in sarcoidosis and then compared serum expression of miRNAs in sarcoidosis patients classified according to the presence of Löfgren's syndrome as a hallmark of good prognosis in comparison to group of patients with more advanced disease course.

\section{Methods}

2.1. Subjects. Serum samples were obtained from 13 healthy controls and 24 patients with pulmonary sarcoidosis according to a standard protocol [11]. Diagnosis of pulmonary sarcoidosis was made according to the criteria of ATS/ERS/ WASOG International Consensus Statement [12]. Löfgren's syndrome was characterized by erythema nodosum, bilateral hilar lymphadenopathy, fever, and polyarthritis. All patients with Löfgren's syndrome had chest X-ray (CXR) stage $\leq 1$ $(n=12)$ and all patients without Löfgren's syndrome had CXR stage $\geq 3(n=12)$. Clinical characteristics and bronchoalveolar cellular profile are provided in Tables 1 and 2, respectively.

All patients were recruited at the Department of Respiratory Medicine and TBC, University Hospital in Olomouc, the Czech Republic. The study was performed with the approval of Ethical committees of Medical Faculty PU \& University Hospital, Olomouc. Informed consent for the anonymous usage of all serum samples for the purposes of the study was obtained from all enrolled subjects. 
2.2. RNA Isolation and RT-PCR. To ensure sample quality without erythrocyte miRNAs contamination, the level of haemolysis in all serum samples was assessed by spectrophotometry (NanoDrop 1000, USA) [11]. No serum sample had A414 reading above a value of 0.2 [13].

Extracellular RNA was isolated from $300 \mu \mathrm{L}$ of serum by using miRCURY ${ }^{\mathrm{TM}}$ RNA isolation kit for biofluids (Exiqon, Denmark). PCR conditions and all reaction mixes were adopted from the user bulletin by Applied Biosystems (Protocol for Creating Custom RT and Preamplification Pools using $\mathrm{TaqMan}^{\circledR}$ MicroRNA Assays).

Briefly, multiplex reverse transcription (RT) was performed with TaqMan MicroRNA Reverse Transcription kit (Applied Biosystems, CA, USA) and RT primer pool prepared by mixing $5 \mathrm{x}$ RT primers provided in TaqMan MicroRNA Assays (Applied Biosystems, CA, USA). To preamplify all tested miRNAs together, TaqMan PreAmp Master Mix was used with PreAmp Primer Pool prepared from 20x TaqMan MicroRNA Assay (Applied Biosystems, CA, USA). qPCRBIO Probe Mix No-ROX (PCR Biosystems, United Kingdom) and 20x TaqMan MicroRNA Assays (Applied Biosystems, CA, USA) were used to perform RT-PCR of individual miRNAs (RotorGene3000 system Corbett Research, Sydney, Australia). All TaqMan MicroRNA Assays are listed in Supplementary material (Online Resource 1 in Supplementary Material available online at http://dx.doi.org/10.1155/ 2016/1246129).

2.3. Data Analysis and Statistics. Second derivative method, described previously in our laboratory [14], was used to assess $\mathrm{Cq}$ and efficiency of RT-PCR. The particular miRNAs were selected based on early published screening data in sarcoidosis $[7,15]$ and our pilot qPCR data that were partly published at European Respiratory Society Congress in 2015 [16]. Only miRNAs with efficiency within 1.7-2.0 (27 miRNAs) were utilised for the subsequent analyses [17] (Supplementary Material/Online Resource 1). GeNorm and NormFinder algorithms were used to reveal a normalisation factor with the highest stability $[18,19]$.

Regarding univariate statistical analysis, Mann-Whitney $U$ test was used to detect possible differences in relative expressions of miRNAs between the study groups. To account for a high false-positive rate possibly caused by a multiple comparison among 3 study groups, correction of $p$ value was performed by using false discovery rate (FDR) method according to Benjamini and Hochberg [20] where desired FDR equaled $5 \%$ and a $p$ value $\leq 0.03$ was considered to be significant.

Multivariate analysis was performed with SIMCA P version 13.5.0 (Umetrics, AB, Umeå, Sweden) by using principle component analysis (PCA) and orthogonal projections to latent structures (OPLS) analysis [21]. Analyses were performed on $\log 2$-transformed, quantile-normalised, meancentered data scaled to unit variance. Model performance is reported as cumulative correlation coefficient for the model $\left(R^{2}\right)$, predictive performance based on 7-fold cross-validation $\left(Q^{2}\right)$, and cross-validated ANOVA (CV-ANOVA) $p$ values for OPLS-based group separation [22].
2.4. Pathway Analysis. MiRSystem (ver. 20150312) was used to assess the possible cumulative effect of the dysregulated miRNAs on gene expression in sarcoidosis [23]. The fold changes of means (patients/controls) of the altered miRNAs were used as an input, including Kyoto Encyclopedia of Genes and Genomes (KEGG) Pathways and an observed-toexpected ratio of greater than 1.0. To balance the reliability of the predictions with a manageable number of records, a number of algorithms predicting the same miRNA-gene interaction pair were set at three algorithm hits, including validated miRNA-gene pairs. Only biological functions/pathways with at least 25 genes and at most 500 genes were analysed.

\section{Results}

3.1. Univariate Analysis of miRNAs in Pulmonary Sarcoidosis. To increase reliability of qPCR data on extracellular miRNAs, several normalisation strategies were tested before own statistical analysis comparing possible differences among study groups. Briefly, both NormFinder and GeNorm algorithms consistently showed a geometric mean of 23 extracellular miRNAs that were expressed in all subjects, to have the lowest expression variability within all samples.

In comparison to healthy controls, we consistently observed the increased expressions of miR-146a-5p and miR16-5p and decreased expressions of miR-425-5p and miR-93$5 p$ in both groups of our sarcoidosis patients with/without Löfgren's syndrome (Figures 1(a)-1(d)). Serum expressions of three miRNAs (miR-150-5p, miR-1, and miR-212-3p) were decreased in our patients without Löfgren's syndrome compared to healthy controls (Figures $2(a)-2(c)$ ). Serum miR21-5p was increased in our patients with Löfgren's syndrome compared to healthy controls. By contrast, miR-340-5p was decreased in the same patients with Löfgren's syndrome compared to healthy controls (Figures 3(a) and 3(b)). The patients without Löfgren's syndrome had decreased expressions of miR-212-3p and miR-21-5p and increased expression of miR$340-5 p$ in comparison with those with Löfgren's syndrome (Figures 2(c), 3(a), and 3(b)).

3.2. Multivariate Analysis of miRNAs in Pulmonary Sarcoidosis. Multivariate analysis was performed to investigate an effect of coexpression of several dysregulated serum miRNAs in sarcoidosis (Supplementary Material/Online Resource 2). Both multivariate analyses of 6 and 7 miRNAs that were dysregulated either in the patients with Löfgren's syndrome or in the patients without Löfgren's syndrome showed consistently that OPLS modelling provides a significant separation between our patients with pulmonary sarcoidosis irrespective of disease course and the healthy controls resulting in the predictive power of $72 \%$ and $65 \%\left(R^{2}=0.737\right.$ and $R^{2}=$ 0.691702 and $Q^{2}=0.717$ and $Q^{2}=0.652 ; p=9.2 \times$ $10^{-7}$ and $p=9.16 \times 10^{-6}$ ) based on 7 -fold cross-validation (Supplementary Material/Online Resource 2). The multivariate modelling with three miRNAs that were dysregulated in the univariate analysis between our patients with Löfgren's syndrome and those without Löfgren's syndrome showed a significant separation with a poor reproducibility in our training data set resulting in the poor predictive power of $44 \%$ 


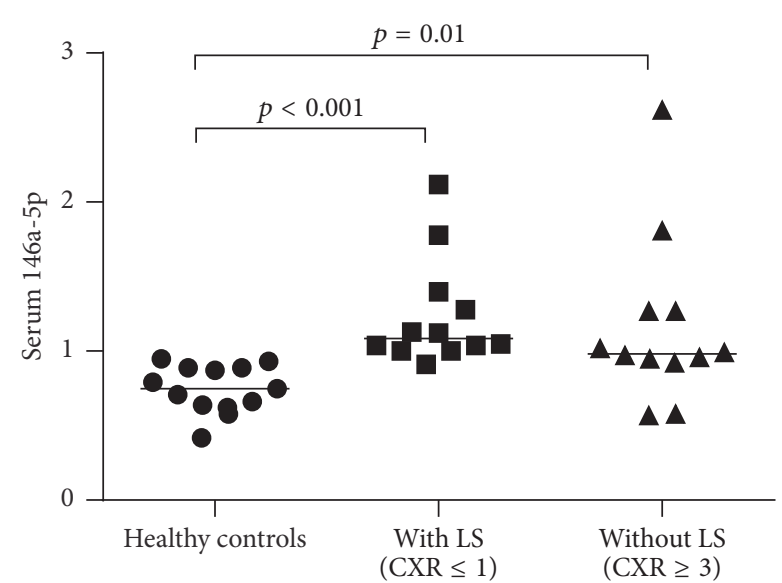

(a)

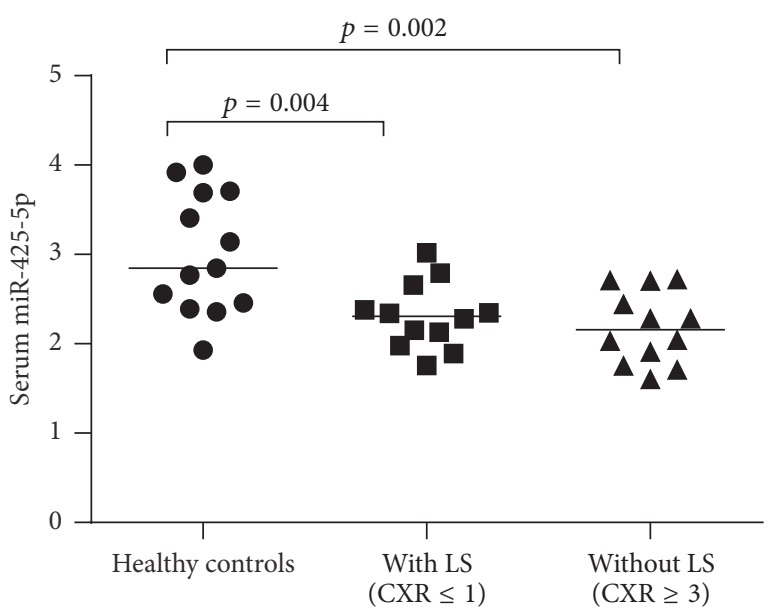

(c)

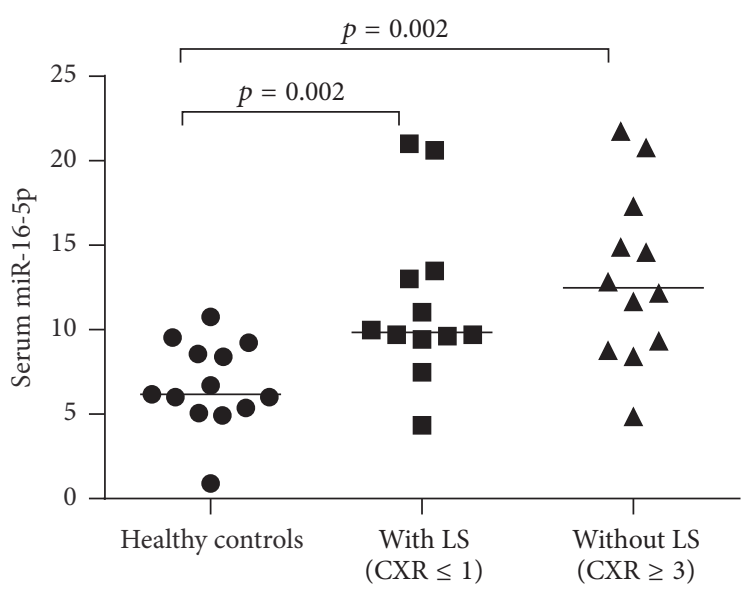

(b)

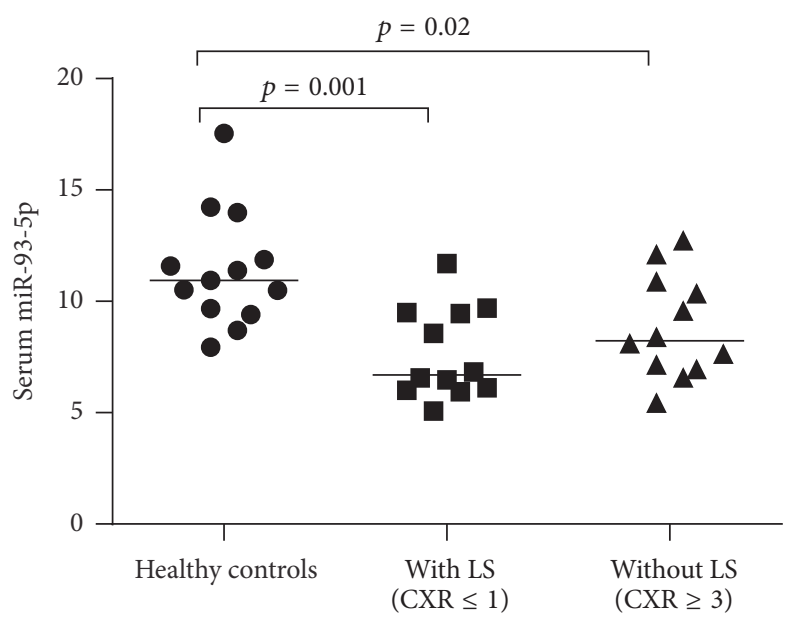

(d)

FIGURE 1: Consistently dysregulated serum miRNAs in both groups of the studied sarcoidosis patients with Löfgren's syndrome and without Löfgren's syndrome compared to healthy controls. CXR, chest X-ray and LS, Löfgren's syndrome.

$\left(R^{2}=0.536\right.$ and $Q^{2}=0.443 ; p=2.2 \times 10^{-3} ;$ Supplementary material/Online resource 2).

3.3. Pathway Analysis. To reveal cumulative effect of the dysregulated miRNAs on gene expression, pathway analysis with miRSystem database was performed. The "Pathways in Cancer" was consistently predicted to be targeted with the highest miRSystem score by both expression profiles that were dysregulated in the patients with/without Löfgren's syndrome compared to healthy controls $\left(p=5.0 \times 10^{-9}\right.$ and $p=9.0 \times 10^{-7}$; Supplementary Material/Online Resource 3). In this pathway, all 6 miRNAs (miR-146a-5p, miR-16-5p, miR425-5p, miR-425-5p, miR-21-5p, and miR-340-5p) that were dysregulated in the patients with Löfgren's syndrome were predicted to modulate 103 target genes based on experimental validation according miRSystem (Table 3). Further, all 7 miRNAs (miR-146a-5p, miR-16-5p, miR-425-5p, miR-425-5p, miR-150-5p, miR-1, and miR-212-3p) that were dysregulated in the patients without Löfgren's syndrome were predicted to modulate 112 target genes based on experimental validation according miRSystem (Table 3 ).
The "Transforming Growth Factor (TGF)- $\beta$ signalling pathway" with its highest miRSystem score among KEGG pathways was predicted to be significantly affected ( $p=$ $1.9 \times 10^{-10}$; Supplementary material/Online Resource 3) by the cumulative effect of three miRNAs whose serum expressions were dysregulated between our patients with Löfgren's syndrome and those without Löfgren's syndrome. In this pathway, three miRNAs (miR-340-5p, miR-212-3p, and miR-21-5p) targeted 25 experimentally validated genes (Table 3).

\section{Discussion}

This work attempts to provide an insight into differential expression of extracellular miRNAs in sarcoidosis patients classified according to the presence of Löfgren's syndrome as a hallmark of good prognosis in comparison to advanced disease course. Our geometric mean-normalised expression showed that serum miR-146a-5p, miR-16-5p, miR-425-5p, and miR-93-5p are consistently dysregulated, regardless of sarcoidosis prognosis, in our patients with pulmonary sarcoidosis compared to healthy controls. Specifically, patients 


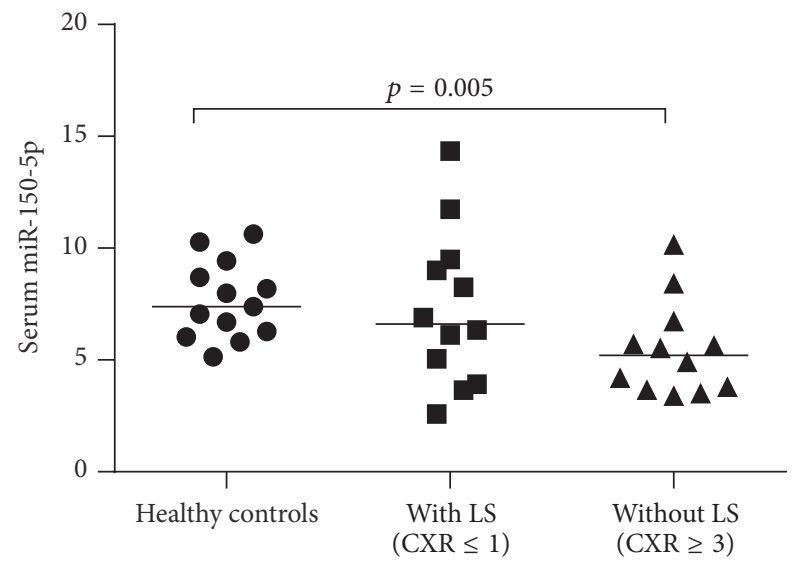

(a)

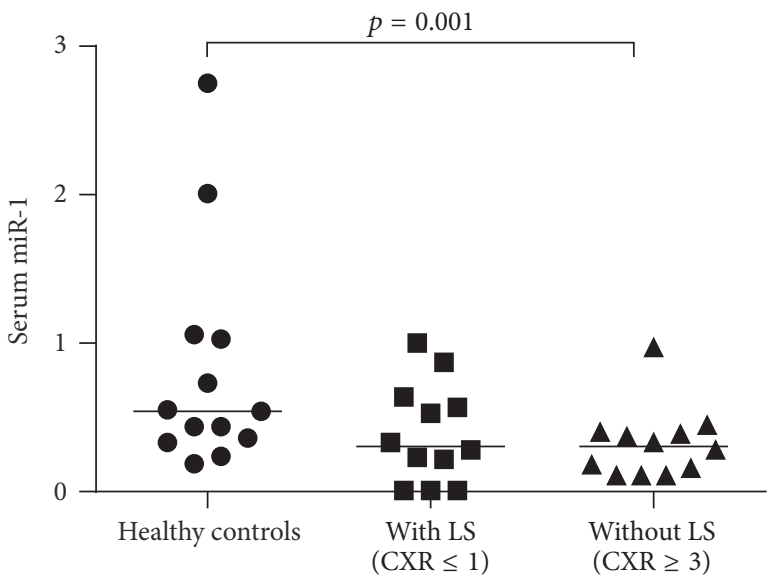

(b)

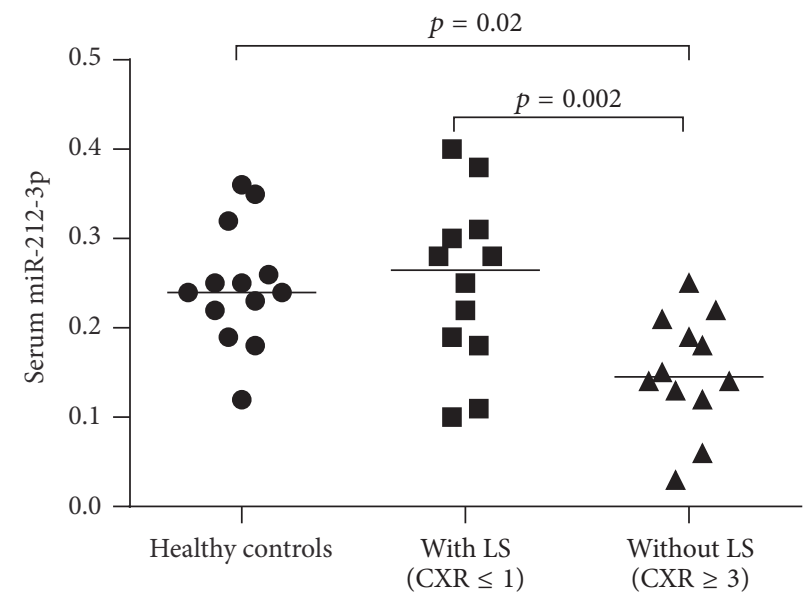

(c)

FIGURE 2: Serum miRNAs only dysregulated in sarcoidosis patients without Löfgren's syndrome compared to healthy controls. CXR, chest $\mathrm{X}$-ray and LS, Löfgren's syndrome.

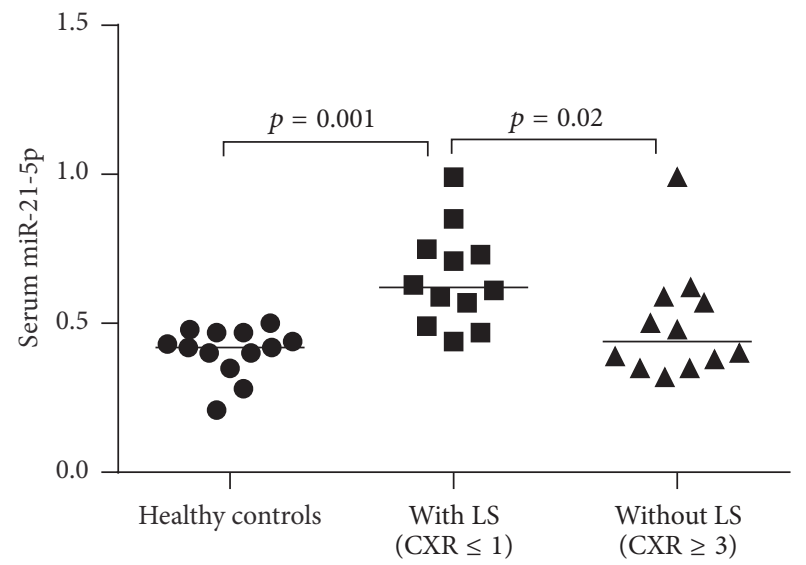

(a)

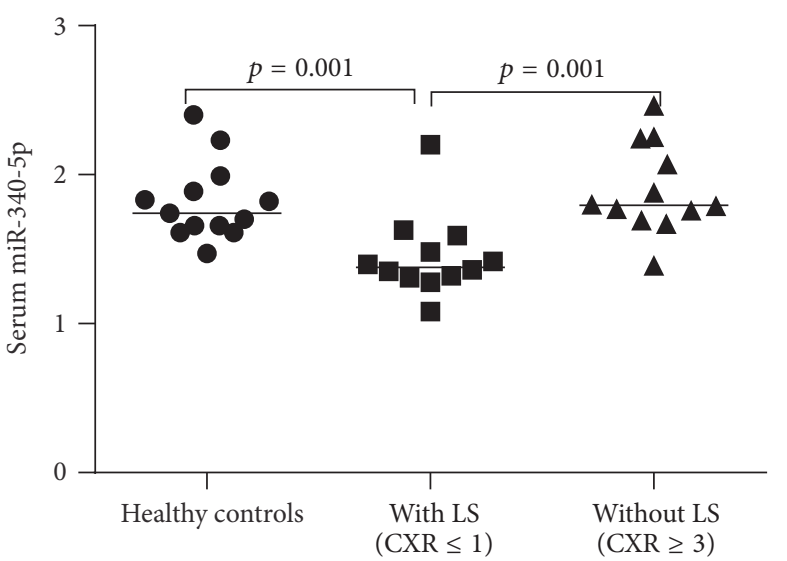

(b)

FIGURE 3: Serum miRNAs only dysregulated in our sarcoidosis patients with Löfgren's syndrome compared to healthy controls. CXR, chest $\mathrm{X}$-ray and LS, Löfgren's syndrome. 
TABLE 3: The target genes that are predicted to be modulated by the dysregulated miRNAs in our patients with sarcoidosis according to miRSystem.

\begin{tabular}{|c|c|c|c|c|c|}
\hline \multirow[b]{2}{*}{ Target gene } & \multirow[b]{2}{*}{ Validation } & \multirow[b]{2}{*}{ Gene description } & \multicolumn{3}{|c|}{ Number of miRNA } \\
\hline & & & $\begin{array}{l}\text { Healthy control } \\
\text { versus LS }\end{array}$ & $\begin{array}{l}\text { Healthy controls } \\
\text { versus CXR III-IV }\end{array}$ & $\begin{array}{l}\text { LS versus CXR } \\
\text { III-IV }\end{array}$ \\
\hline ACVR1 & $\mathrm{V}$ & Activin A receptor, type I & 0 & 0 & 1 \\
\hline ACVR1C & $\mathrm{V}$ & Activin A receptor, type IC & 0 & 0 & 1 \\
\hline ACVR2A & $\mathrm{V}$ & Activin A receptor, type IIA & 0 & 0 & 1 \\
\hline ACVR2B & $\mathrm{V}$ & Activin A receptor, type IIB & 0 & 0 & 3 \\
\hline AKT3 & $\mathrm{V}$ & v-akt murine thymoma viral oncogene homolog 3 & 2 & 3 & 0 \\
\hline APC & $\mathrm{V}$ & Adenomatous polyposis coli & 0 & 1 & 0 \\
\hline APPL1 & $\mathrm{V}$ & $\begin{array}{l}\text { Adaptor protein, phosphotyrosine interaction, } \mathrm{PH} \\
\text { domain and leucine zipper containing } 1\end{array}$ & 2 & 1 & 0 \\
\hline ARNT & $\mathrm{V}$ & Aryl hydrocarbon receptor nuclear translocator & 1 & 3 & 0 \\
\hline AXIN2 & $\mathrm{V}$ & Axin 2 & 1 & 1 & 0 \\
\hline BCL2 & $\mathrm{V}$ & B-cell CLL/lymphoma 2 & 3 & 3 & 0 \\
\hline BCR & $\mathrm{V}$ & Breakpoint cluster region & 2 & 2 & 0 \\
\hline BMPR2 & $\mathrm{V}$ & $\begin{array}{l}\text { Bone morphogenetic protein receptor, type II } \\
\text { (serine/threonine kinase) }\end{array}$ & 0 & 0 & 2 \\
\hline BRCA2 & $\mathrm{V}$ & Breast cancer 2, early onset & 1 & 1 & 0 \\
\hline CASP8 & $\mathrm{V}$ & Caspase 8 , apoptosis-related cysteine peptidase & 1 & 1 & 0 \\
\hline CBL & $\mathrm{V}$ & Cbl proto-oncogene, E3 ubiquitin protein ligase & 1 & 3 & 0 \\
\hline CCDC6 & $\mathrm{V}$ & Coiled-coil domain containing 6 & 2 & 2 & 0 \\
\hline CCND1 & $\mathrm{V}$ & Cyclin D1 & 2 & 3 & 0 \\
\hline CCNE1 & $\mathrm{V}$ & Cyclin E1 & 1 & 2 & 0 \\
\hline $\mathrm{CDC} 42$ & $\mathrm{~V}$ & Cell division cycle 42 & 1 & 2 & 0 \\
\hline CDK6 & $\mathrm{V}$ & Cyclin-dependent kinase 6 & 4 & 4 & 0 \\
\hline CDKN1A & $\mathrm{V}$ & Cyclin-dependent kinase inhibitor 1A (p21, Cip1) & 2 & 2 & 0 \\
\hline COL4A1 & $\mathrm{V}$ & Collagen, type IV, alpha 1 & 2 & 1 & 0 \\
\hline COL4A4 & $\mathrm{V}$ & Collagen, type IV, alpha 4 & & 1 & 0 \\
\hline CRK & $\mathrm{V}$ & v-crk avian sarcoma virus CT10 oncogene homolog & 1 & 3 & 0 \\
\hline CRKL & $\mathrm{V}$ & $\begin{array}{c}\text { v-crk avian sarcoma virus CT10 oncogene } \\
\text { homolog-like }\end{array}$ & 1 & 1 & 0 \\
\hline СТВР2 & $\mathrm{V}$ & C-terminal binding protein 2 & 0 & 1 & 0 \\
\hline CTNNB1 & $\mathrm{V}$ & Catenin (cadherin-associated protein), beta $1,88 \mathrm{kDa}$ & 1 & 1 & 0 \\
\hline CUL2 & $\mathrm{V}$ & Cullin 2 & 1 & 1 & 0 \\
\hline CYCS & $\mathrm{V}$ & Cytochrome c, somatic & 1 & 1 & 0 \\
\hline DVL1 & $\mathrm{V}$ & Dishevelled segment polarity protein 1 & 1 & 1 & 0 \\
\hline E2F1 & $\mathrm{V}$ & E2F transcription factor 1 & 2 & 1 & 0 \\
\hline $\mathrm{E} 2 \mathrm{~F} 2$ & $\mathrm{~V}$ & E2F transcription factor 2 & 1 & 1 & 0 \\
\hline $\mathrm{E} 2 \mathrm{~F} 3$ & $\mathrm{~V}$ & E2F transcription factor 3 & 3 & 3 & 0 \\
\hline E2F5 & $\mathrm{V}$ & E2F transcription factor 5, p130-binding & 0 & 0 & 1 \\
\hline EGLN1 & $\mathrm{V}$ & egl-9 family hypoxia-inducible factor 1 & 1 & 1 & 0 \\
\hline EGLN2 & $\mathrm{V}$ & egl-9 family hypoxia-inducible factor 2 & 1 & 1 & 0 \\
\hline EGLN3 & $\mathrm{V}$ & egl-9 family hypoxia-inducible factor 3 & 1 & 1 & 0 \\
\hline EP300 & $\mathrm{V}$ & E1A binding protein $\mathrm{p} 300$ & & 2 & 1 \\
\hline EPAS1 & $\mathrm{V}$ & endothelial PAS domain protein 1 & 2 & 1 & 0 \\
\hline ETS1 & $\mathrm{V}$ & $\begin{array}{l}\text { v-ets avian erythroblastosis virus E26 oncogene } \\
\text { homolog } 1\end{array}$ & 0 & 1 & 0 \\
\hline FADD & $\mathrm{V}$ & Fas (TNFRSF6)-associated via death domain & 1 & 1 & 0 \\
\hline FAS & $\mathrm{V}$ & Fas cell surface death receptor & 2 & 1 & 0 \\
\hline FASLG & $\mathrm{V}$ & Fas ligand (TNF superfamily, member 6) & 1 & 0 & 0 \\
\hline
\end{tabular}


TABle 3: Continued.

\begin{tabular}{|c|c|c|c|c|c|}
\hline \multirow[b]{2}{*}{ Target gene } & \multirow[b]{2}{*}{ Validation } & \multirow[b]{2}{*}{ Gene description } & \multicolumn{3}{|c|}{ Number of miRNA } \\
\hline & & & $\begin{array}{l}\text { Healthy control } \\
\text { versus LS }\end{array}$ & $\begin{array}{l}\text { Healthy controls } \\
\text { versus CXR III-IV }\end{array}$ & $\begin{array}{l}\text { LS versus CXR } \\
\text { III-IV }\end{array}$ \\
\hline FGF1 & $\mathrm{V}$ & Fibroblast growth factor 1 (acidic) & 1 & 0 & 0 \\
\hline FGF13 & $\mathrm{V}$ & Fibroblast growth factor 13 & 1 & 0 & 0 \\
\hline FGF14 & $\mathrm{V}$ & fibroblast growth Factor 14 & 0 & 1 & 0 \\
\hline FGF2 & $\mathrm{V}$ & Fibroblast growth factor 2 (basic) & 1 & 1 & 0 \\
\hline FGF4 & $\mathrm{V}$ & Fibroblast growth factor 4 & 1 & 1 & 0 \\
\hline FGF7 & $\mathrm{V}$ & Fibroblast growth factor 7 & 3 & 3 & 0 \\
\hline FGF9 & $\mathrm{V}$ & Fibroblast growth factor 9 & 1 & 1 & 0 \\
\hline FGFR1 & $\mathrm{V}$ & Fibroblast growth factor receptor 1 & 1 & 1 & 0 \\
\hline FGFR2 & $\mathrm{V}$ & Fibroblast growth factor receptor 2 & 1 & 1 & 0 \\
\hline FIGF & $\mathrm{V}$ & $\begin{array}{l}\text { c-fos induced growth factor (vascular endothelial } \\
\text { growth factor D) }\end{array}$ & 1 & 1 & 0 \\
\hline FLT3 & $\mathrm{V}$ & fms-related tyrosine kinase 3 & 1 & 1 & 0 \\
\hline FN1 & $\mathrm{V}$ & Fibronectin 1 & & 1 & 0 \\
\hline FOXO1 & $\mathrm{V}$ & Forkhead box O1 & 1 & 1 & 0 \\
\hline FZD1 & $\mathrm{V}$ & Frizzled family receptor 1 & 1 & 1 & 0 \\
\hline FZD10 & $\mathrm{V}$ & Frizzled family receptor 10 & 1 & 1 & 0 \\
\hline FZD4 & $\mathrm{V}$ & Frizzled family receptor 4 & 0 & 1 & 0 \\
\hline FZD7 & $\mathrm{V}$ & Frizzled family receptor 7 & 0 & 1 & 0 \\
\hline GDF5 & $\mathrm{V}$ & Growth differentiation factor 5 & 0 & 0 & 1 \\
\hline GRB2 & $\mathrm{V}$ & Growth factor receptor-bound protein 2 & 1 & 1 & 0 \\
\hline HHIP & $\mathrm{V}$ & Hedgehog interacting protein & 0 & 1 & 0 \\
\hline HIF1A & $\mathrm{V}$ & $\begin{array}{l}\text { Hypoxia inducible factor 1, alpha subunit (basic } \\
\text { helix-loop-helix transcription factor) }\end{array}$ & 1 & 1 & 0 \\
\hline HSP90B1 & $\mathrm{V}$ & Heat shock protein $90 \mathrm{kDa}$ beta (Grp94), member 1 & 0 & 2 & 0 \\
\hline CHUK & $\mathrm{V}$ & Conserved helix-loop-helix ubiquitous kinase & 1 & 1 & 0 \\
\hline IGF1 & $\mathrm{V}$ & Insulin-like growth factor 1 (somatomedin $\mathrm{C}$ ) & 2 & 2 & 0 \\
\hline IGF1R & $\mathrm{V}$ & Insulin-like growth factor 1 receptor & 1 & 1 & 0 \\
\hline IKBKB & $\mathrm{V}$ & $\begin{array}{c}\text { Inhibitor of kappa light polypeptide gene enhancer in } \\
\text { B-cells, kinase beta }\end{array}$ & 1 & 2 & 0 \\
\hline IL8 & $\mathrm{V}$ & Interleukin 8 & 1 & 1 & 0 \\
\hline ITGA2 & $\mathrm{V}$ & $\begin{array}{c}\text { Integrin, alpha } 2 \text { (CD49B, alpha } 2 \text { subunit of VLA-2 } \\
\text { receptor) }\end{array}$ & 1 & 1 & 0 \\
\hline ITGA3 & $\mathrm{V}$ & $\begin{array}{c}\text { Integrin, alpha } 3 \text { (antigen CD49C, alpha } 3 \text { subunit of } \\
\text { VLA-3 receptor) }\end{array}$ & 0 & 1 & 0 \\
\hline ITGA6 & $\mathrm{V}$ & Integrin, alpha 6 & 1 & 0 & 0 \\
\hline ITGAV & $\mathrm{V}$ & Integrin, alpha $\mathrm{V}$ & 1 & 0 & 0 \\
\hline JAK1 & $\mathrm{V}$ & Janus kinase 1 & 2 & 1 & 0 \\
\hline JUN & $\mathrm{V}$ & Jun proto-oncogene & 1 & 1 & 0 \\
\hline KRAS & $\mathrm{V}$ & Kirsten rat sarcoma viral oncogene homolog & 1 & 3 & 0 \\
\hline LAMA3 & $\mathrm{V}$ & Laminin, alpha 3 & 1 & 1 & 0 \\
\hline LAMC1 & $\mathrm{V}$ & Laminin, gamma 1 (formerly LAMB2) & 2 & 2 & 0 \\
\hline LAMC2 & $\mathrm{V}$ & Laminin, gamma 2 & 0 & 2 & 0 \\
\hline LTBP1 & $\mathrm{V}$ & $\begin{array}{l}\text { Latent transforming growth factor beta binding } \\
\text { protein } 1\end{array}$ & 0 & 0 & 1 \\
\hline MAP2K1 & $\mathrm{V}$ & Mitogen-activated protein kinase kinase 1 & 1 & 1 & 0 \\
\hline MAPK1 & $\mathrm{V}$ & Mitogen-activated protein kinase 1 & 1 & 3 & 1 \\
\hline MAPK10 & $\mathrm{V}$ & Mitogen-activated protein kinase 10 & 1 & 0 & 0 \\
\hline MAPK3 & $\mathrm{V}$ & Mitogen-activated protein kinase 3 & 0 & 1 & 0 \\
\hline MAPK9 & $\mathrm{V}$ & Mitogen-activated protein kinase 9 & 2 & 3 & 0 \\
\hline
\end{tabular}


TABle 3: Continued.

\begin{tabular}{|c|c|c|c|c|c|}
\hline \multirow[b]{2}{*}{ Target gene } & \multirow[b]{2}{*}{ Validation } & \multirow[b]{2}{*}{ Gene description } & \multicolumn{3}{|c|}{ Number of miRNA } \\
\hline & & & $\begin{array}{l}\text { Healthy control } \\
\text { versus LS }\end{array}$ & $\begin{array}{l}\text { Healthy controls } \\
\text { versus CXR III-IV }\end{array}$ & $\begin{array}{l}\text { LS versus CXR } \\
\text { III-IV }\end{array}$ \\
\hline MET & $\mathrm{V}$ & Met proto-oncogene & 0 & 1 & 0 \\
\hline MITF & $\mathrm{V}$ & Microphthalmia-associated transcription factor & 1 & 0 & 0 \\
\hline MMP2 & $\mathrm{V}$ & $\begin{array}{l}\text { Matrix metallopeptidase } 2 \text { (gelatinase } \mathrm{A}, 72 \mathrm{kDa} \\
\text { gelatinase, } 72 \mathrm{kDa} \text { type IV collagenase) }\end{array}$ & 1 & 1 & 0 \\
\hline MSH2 & $\mathrm{V}$ & mutS homolog 2 & 2 & 1 & 0 \\
\hline NRAS & $\mathrm{V}$ & Neuroblastoma RAS viral (v-ras) oncogene homolog & 1 & 1 & 0 \\
\hline PDGFA & $\mathrm{V}$ & Platelet-derived growth factor alpha polypeptide & 0 & 1 & 0 \\
\hline PDGFRA & $\mathrm{V}$ & $\begin{array}{l}\text { Platelet-derived growth factor receptor, alpha } \\
\text { polypeptide }\end{array}$ & 2 & 1 & 0 \\
\hline PIAS1 & $\mathrm{V}$ & Protein inhibitor of activated STAT, 1 & 1 & 1 & 0 \\
\hline PIAS3 & $\mathrm{V}$ & Protein inhibitor of activated STAT, 3 & 0 & 1 & 0 \\
\hline PIK3R1 & $\mathrm{V}$ & $\begin{array}{l}\text { Phosphoinositide-3-kinase, regulatory subunit } 1 \\
\text { (alpha) }\end{array}$ & 3 & 4 & 0 \\
\hline PIK3R3 & $\mathrm{V}$ & $\begin{array}{l}\text { Phosphoinositide-3-kinase, regulatory subunit } 3 \\
\text { (gamma) }\end{array}$ & 1 & 2 & 0 \\
\hline PITX2 & $\mathrm{V}$ & Paired-like homeodomain 2 & 0 & 0 & 1 \\
\hline PPP2CB & $\mathrm{V}$ & Protein phosphatase 2 , catalytic subunit, beta isozyme & 0 & 0 & 1 \\
\hline PRKCA & $\mathrm{V}$ & Protein kinase C, alpha & 1 & 1 & 0 \\
\hline PTEN & $\mathrm{V}$ & Phosphatase and tensin homolog & 2 & 1 & 0 \\
\hline PTCH1 & $\mathrm{V}$ & Patched 1 & 1 & 2 & 0 \\
\hline RAC1 & $\mathrm{V}$ & $\begin{array}{l}\text { Ras-related C3 botulinum toxin substrate } 1 \text { (rho } \\
\text { family, small GTP binding protein Rac1) }\end{array}$ & 1 & 0 & 0 \\
\hline RAF1 & $\mathrm{V}$ & v-raf-1 murine leukemia viral oncogene homolog 1 & 1 & 1 & 0 \\
\hline RALA & $\mathrm{V}$ & $\begin{array}{l}\text { v-ral simian leukemia viral oncogene homolog A (ras } \\
\text { related) }\end{array}$ & 0 & 1 & 0 \\
\hline RALBP1 & $\mathrm{V}$ & ralA binding protein 1 & 2 & 1 & 0 \\
\hline RARB & $\mathrm{V}$ & Retinoic acid receptor, beta & 2 & 3 & 0 \\
\hline RASSF5 & $\mathrm{V}$ & $\begin{array}{c}\text { Ras association (RalGDS/AF-6) domain family } \\
\text { member } 5\end{array}$ & 1 & 1 & 0 \\
\hline RB1 & $\mathrm{V}$ & Retinoblastoma 1 & 1 & 2 & 0 \\
\hline RET & $\mathrm{V}$ & Ret proto-oncogene & 1 & 1 & 0 \\
\hline RHOA & $\mathrm{V}$ & Ras homolog family member A & 1 & 0 & 1 \\
\hline ROCK1 & $\mathrm{V}$ & Rho-associated, coiled-coil containing protein kinase 1 & 0 & 0 & 1 \\
\hline RPS6KB1 & $\mathrm{V}$ & Ribosomal protein S6 kinase, 70 kDa, polypeptide 1 & 0 & 0 & 1 \\
\hline RUNX1 & $\mathrm{V}$ & Runt-related transcription factor 1 & 1 & 2 & 0 \\
\hline RUNX1T1 & $\mathrm{V}$ & $\begin{array}{l}\text { Runt-related transcription factor 1; translocated to, } 1 \\
\text { (cyclin D-related) }\end{array}$ & 3 & 2 & 0 \\
\hline SLC2A1 & $\mathrm{V}$ & $\begin{array}{c}\text { Solute carrier family } 2 \text { (facilitated glucose } \\
\text { transporter), member } 1\end{array}$ & 0 & 2 & 0 \\
\hline SMAD2 & $\mathrm{V}$ & SMAD family member 2 & 2 & 2 & 2 \\
\hline SMAD3 & $\mathrm{V}$ & SMAD family member 3 & 1 & 1 & 0 \\
\hline SMAD4 & $\mathrm{V}$ & SMAD family member 4 & 1 & 1 & 0 \\
\hline SMAD5 & $\mathrm{V}$ & SMAD family member 5 & 0 & 0 & 1 \\
\hline SMAD7 & $\mathrm{V}$ & SMAD family member 7 & 0 & 0 & 1 \\
\hline SMURF1 & $\mathrm{V}$ & SMAD specific E3 ubiquitin protein ligase 1 & 0 & 0 & 1 \\
\hline STAT1 & $\mathrm{V}$ & $\begin{array}{l}\text { Signal transducer and activator of transcription } 1, \\
\qquad 91 \mathrm{kDa}\end{array}$ & 1 & 1 & 0 \\
\hline STAT3 & $\mathrm{V}$ & $\begin{array}{l}\text { Signal transducer and activator of transcription } 3 \\
\text { (acute-phase response factor) }\end{array}$ & 2 & 1 & 0 \\
\hline
\end{tabular}


TABLE 3: Continued.

\begin{tabular}{|c|c|c|c|c|c|}
\hline \multirow[b]{2}{*}{ Target gene } & \multirow[b]{2}{*}{ Validation } & \multirow[b]{2}{*}{ Gene description } & \multicolumn{3}{|c|}{ Number of miRNA } \\
\hline & & & $\begin{array}{l}\text { Healthy control } \\
\text { versus LS }\end{array}$ & $\begin{array}{l}\text { Healthy controls } \\
\text { versus CXR III-IV }\end{array}$ & $\begin{array}{l}\text { LS versus CXR } \\
\text { III-IV }\end{array}$ \\
\hline STK4 & $\mathrm{V}$ & Serine/threonine kinase 4 & & 1 & 0 \\
\hline TCF7 & $\mathrm{V}$ & Transcription factor 7 (T-cell specific, HMG-box) & 1 & 1 & 0 \\
\hline TCF7L1 & $\mathrm{V}$ & $\begin{array}{c}\text { Transcription factor 7-like } 1 \text { (T-cell specific, } \\
\text { HMG-box) }\end{array}$ & 2 & 2 & 0 \\
\hline TCF7L2 & $\mathrm{V}$ & $\begin{array}{c}\text { Transcription factor 7-like } 2 \text { (T-cell specific, } \\
\text { HMG-box) }\end{array}$ & 0 & 1 & 0 \\
\hline TFDP1 & $\mathrm{V}$ & Transcription factor $\mathrm{Dp}-1$ & 0 & 0 & 1 \\
\hline TGFB1 & $\mathrm{V}$ & Transforming growth factor, beta 1 & 1 & 0 & 1 \\
\hline TGFBR1 & $\mathrm{V}$ & Transforming growth factor, beta receptor 1 & 1 & 0 & 1 \\
\hline TGFBR2 & $\mathrm{V}$ & $\begin{array}{l}\text { Transforming growth factor, beta receptor II } \\
\qquad(70 / 80 \mathrm{kDa})\end{array}$ & 2 & 1 & 1 \\
\hline THBS1 & $\mathrm{V}$ & Thrombospondin 1 & 0 & 0 & 1 \\
\hline TPM3 & $\mathrm{V}$ & Tropomyosin 3 & 1 & 2 & 0 \\
\hline TRAF6 & $\mathrm{V}$ & $\begin{array}{c}\text { TNF receptor-associated factor } 6, \mathrm{E} 3 \text { ubiquitin protein } \\
\text { ligase }\end{array}$ & 1 & 1 & 0 \\
\hline VEGFA & $\mathrm{V}$ & Vascular endothelial growth factor A & 2 & 3 & 0 \\
\hline VHL & $\mathrm{V}$ & $\begin{array}{l}\text { Von Hippel-Lindau tumor suppressor, E3 ubiquitin } \\
\text { protein ligase }\end{array}$ & 1 & 1 & 0 \\
\hline WNT11 & $\mathrm{V}$ & $\begin{array}{c}\text { Wingless-type MMTV integration site family, } \\
\text { member } 11\end{array}$ & 1 & 0 & 0 \\
\hline WNT3A & $\mathrm{V}$ & $\begin{array}{l}\text { Wingless-type MMTV integration site family, } \\
\text { member } 3 \mathrm{~A}\end{array}$ & 1 & 1 & 0 \\
\hline WNT7A & $\mathrm{V}$ & $\begin{array}{l}\text { Wingless-type MMTV integration site family, } \\
\text { member 7A }\end{array}$ & 1 & 1 & 0 \\
\hline XIAP & $\mathrm{V}$ & X-linked inhibitor of apoptosis & 1 & 1 & 0 \\
\hline ZFYVE16 & $\mathrm{V}$ & Zinc finger, FYVE domain containing 16 & 0 & 0 & 2 \\
\hline
\end{tabular}

CXR, chest X-ray; LS, Löfgren's syndrome; V, min. one miRNA has experimental validation in miRSystem; 0 , none of the dysregulated miRNAs.

without Löfgren's syndrome had dysregulated expressions of miR-150-5p, miR-1, and miR-212-3p and those with Löfgren's syndrome had dysregulated miR-21-5p and miR-340-5p in comparison to healthy controls. MiRSystem predicted the Pathways in cancer to be consistently affected by both of the dysregulated expression profiles in sarcoidosis with/without Löfgren's syndrome. Three serum miRNAs (miR-21-5p, miR340-5p, and miR-212-3p) differed between the sarcoidosis patients with Löfgren's syndrome and those without Löfgren's syndrome. Their cumulative effect may modulate the "transforming growth factor (TGF)- $\beta$ signalling pathway" during sarcoidosis progression.

Because of a lack of current knowledge on stably expressed extracellular miRNAs in serum from the patients with sarcoidosis, the best approach of qPCR data normalisation was investigated at the earliest. A geometric mean of all expressed extracellular miRNAs showed the best stability and was therefore used to normalise the raw qPCR data in subsequent analysis comparing the study groups. The geometric mean-normalisation is different from that used by Jazwa et al. who measured like our paper serum expressions of miR-16-5p, miR-146a-5p, and miR-150-5p in sarcoidosis patients [7]. They did not find any of these serum miRNAs to be dysregulated in pulmonary sarcoidosis. It is in contrast with our observations and could be explain by the different normalisation approach in combination with different representation of CXR stages among the sarcoidosis patients in the study by Jazwa et al. [7].

In comparison with our healthy controls, dysregulation of 4 miRNAs was consistently presented in sarcoidosis as a whole. However, we also observed several miRNAs to be associated with either the presence of Löfgren's syndrome or its absence. Through these differences, the "Pathways in Cancer" was consistently predicted to be modulated by cumulative effect of both of the serum expressions profiles in pulmonary sarcoidosis with/without Löfgren's syndrome. Remarkably, an increased risk of cancer is discussed in sarcoidosis patients and the presence of sarcoidosis granuloma has been reported in case studies on oncology patients [24-26]. This relationship has been also supported by other authors [27]. The dysregulation of serum miRNAs in our sarcoidosis patients may therefore result from the inflammation, apoptosis, and angiogenesis frequently accompanying various malignant processes [28-30] and it likely may not be directly related to presence/absence of Löfgren's syndrome in sarcoidosis.

In addition, several particular target genes of the "Pathways in Cancer" have been indeed indicated in wet laboratory to be dysregulated at their protein and/or mRNA level in sarcoidosis [31-36]. Among them, WNT (wingless and integrase-1)7A, catenin-beta, and transforming growth 
factor- (TGF-) $\beta$ are concurrently involved into other signalling pathways, including the WNT and TGF- $\beta$ signalling pathways [23]. Both of these signalling pathways were already once predicted to be modulated by cumulative effect of several intracellular miRNAs that are dysregulated in the peripheral blood lymphocytes and the lung tissue obtained from sarcoidosis patients [6].

In line with the intracellular miRNAs-based prediction [6], the "TGF- $\beta$ signalling pathway" was predicted here to be affected by the extracellular serum miRNAs (miR-21$5 p$, miR-340-5p, and miR-212-3p) that differed between our patients with Löfgren's syndrome and those without Löfgren's syndrome. Taking into consideration a profibrotic character of TGF- $\beta$ action [37], it is notable that the "TGF- $\beta$ signalling pathway" was predicted here although only two patients with fibrotic changes (CXR stage IV) were enrolled in this study. Besides them, the other patients without Löfgren's syndrome had CXR stage III in this work. We may therefore speculate on an incipient fibrotic process that involves posttranscriptional regulation beginning before CXR stage IV. On the other hand, our patients with CXR stage $\geq 3$ did not have dysregulated expression of miR-21 whose elevation has been associated with IPF [38].

Thus, comparison among all 5 CXR stages needs to be elucidated to gain a whole insight into the disease course ranging from invisible abnormality of the intrathoracic lymph nodes toward the lung parenchymal involvement and lung fibrosis in the most advanced sarcoidosis [1]. This could even reveal the key regulatory player leading to the disease remission that is known to be common (55-90\%) in early disease (namely, in Löfgren's syndrome) whereas rare (10-20\%) and absent in CXR stage III and IV, respectively.

Our multivariate analysis showed significant separation between our sarcoidosis patients and healthy controls. However, three miRNAs (miR-21-5p, miR-340-5p, and miR-212$3 p$ ) did not provide good model to separate our sarcoidosis patients according to the presence/absence of Löfgren's syndrome. The lack of profound differences between two groups of our patients with sarcoidosis is in line with current poor knowledge on any sufficiently sensitive and specific serum profile for the disease course [39]. This seems not to stand for genetic background as several genetic variants have been reported to be associated with Löfgren's syndrome [40-42].

It should be noted that some miRNAs with plausible relevance for sarcoidosis pathogenesis were not investigated and this could represent a limitation of our study. Our multiplex qPCR method did not also allow us to perform any high-throughput screening, although we assessed higher number of serum miRNA than a previous study on serum miRNAs in sarcoidosis [7]. Our selection was based on the current knowledge on intracellular miRNAs in pulmonary sarcoidosis $[6,15]$. Taking into consideration different biological properties, for example, the broadly discussed processing during cell-cell communication, intracellular miRNAs are unlikely to be dysregulated in parallel with their intracellular expression [43]. Thus, a high-throughput screening for extracellular miRNAs may reveal new serum biomarkers of sarcoidosis and the disease prognosis.
In conclusion, we report several serum miRNAs to be associated with pulmonary sarcoidosis and also further differences between our sarcoidosis patients stratified according to the presence/absence of Löfgren's syndrome as a hallmark of good prognosis. In an attempt to link the serum miRNAs to certain biological processes using bioinformatics tools, the "Pathways in Cancer" was predicted to be related to pulmonary sarcoidosis as a whole whereas the "TGF-beta signalling pathway" was predicted to be related to the disease course. The complex interplay between the serum miRNAs and the predicted target genes of these signalling pathways remains the matter of future experimental investigation to gain detailed insight into the pathological mechanisms underlying the disease and its advancement.

\section{Funding}

The work was supported by Grant Projects LO1304, CZ.1.07/2.3.00/30.0004, and IGA PU LF 2015_030, 2016_009.

\section{Competing Interests}

The authors declare that they have no competing interests.

\section{References}

[1] D. Valeyre, A. Prasse, H. Nunes, Y. Uzunhan, P.-Y. Brillet, and J. Müller-Quernheim, "Sarcoidosis," The Lancet, vol. 383, no. 9923, pp. 1155-1167, 2014.

[2] G. Zissel and J. Müller-Quernheim, "Specific antigen(s) in sarcoidosis: a link to autoimmunity?" European Respiratory Journal, vol. 47, no. 3, pp. 707-709, 2016.

[3] S. L. Ameres and P. D. Zamore, "Diversifying microRNA sequence and function," Nature Reviews Molecular Cell Biology, vol. 14, no. 8, pp. 475-488, 2013.

[4] J. Kiszałkiewicz, W. J. Piotrowski, D. Pastuszak-Lewandoska et al., "Altered miRNA expression in pulmonary sarcoidosis," BMC Medical Genetics, vol. 17, no. 1, article 2, 12 pages, 2016.

[5] T. Dyskova, R. Fillerova, T. Novosad et al., "Correlation network analysis reveals relationships between MicroRNAs, transcription factor T-bet, and deregulated cytokine/chemokinereceptor network in pulmonary sarcoidosis," Mediators of Inflammation, vol. 2015, Article ID 121378, 16 pages, 2015.

[6] E. D. Crouser, M. W. Julian, M. Crawford et al., "Differential expression of microRNA and predicted targets in pulmonary sarcoidosis," Biochemical and Biophysical Research Communications, vol. 417, no. 2, pp. 886-891, 2012.

[7] A. Jazwa, L. Kasper, M. Bak et al., "Differential inflammatory MicroRNA and cytokine expression in pulmonary sarcoidosis," Archivum Immunologiae et Therapiae Experimentalis, vol. 63, no. 2, pp. 139-146, 2015.

[8] J. A. Weber, D. H. Baxter, S. Zhang et al., "The microRNA spectrum in 12 body fluids," Clinical Chemistry, vol. 56, no. 11, pp. 1733-1741, 2010.

[9] K. R. Qazi, P. T. Paredes, B. Dahlberg, J. Grunewald, A. Eklund, and S. Gabrielsson, "Proinflammatory exosomes in bronchoalveolar lavage fluid of patients with sarcoidosis," Thorax, vol. 65, no. 11, pp. 1016-1024, 2010.

[10] F. Marabita, P. de Candia, A. Torri, J. Tegnér, S. Abrignani, and R. L. Rossi, "Normalization of circulating microRNA expression 
data obtained by quantitative real-time RT-PCR," Briefings in Bioinformatics, vol. 17, no. 2, pp. 204-212, 2015.

[11] K. W. Witwer, E. I. Buzás, L. T. Bemis et al., "Standardization of sample collection, isolation and analysis methods in extracellular vesicle research," Journal of Extracellular Vesicles, vol. 2, Article ID 20360, 2013.

[12] "Statement on sarcoidosis. Joint Statement of the American Thoracic Society (ATS), the European Respiratory Society (ERS) and the World Association of Sarcoidosis and Other Granulomatous Disorders (WASOG) adopted by the ATS Board of Directors and by the ERS Executive Committee, February 1999," American Journal of Respiratory and Critical Care Medicine, vol. 160, no. 2, pp. 736-755, 1999.

[13] M. B. Kirschner, J. J. B. Edelman, S. C.-H. Kao, M. P. Vallely, N. van Zandwijk, and G. Reid, "The impact of hemolysis on cellfree microRNA biomarkers," Frontiers in Genetics, vol. 4, article 94, 2013.

[14] E. Kriegova, A. Arakelyan, R. Fillerova et al., "PSMB2 and RPL32 are suitable denominators to normalize gene expression profiles in bronchoalveolar cells," BMC Molecular Biology, vol. 9, article 69, pp. 1471-2199, 2008.

[15] J. Maertzdorf, J. Weiner III, H.-J. Mollenkopf et al., "Common patterns and disease-related signatures in tuberculosis and sarcoidosis," Proceedings of the National Academy of Sciences of the United States of America, vol. 109, no. 20, pp. 7853-7858, 2012.

[16] Z. Navratilova, E. Novosadova, D. Smitalova, A. Kishore, V. Kolek, and M. Petrek, "Serum and bronchoalveolar exosomal miRNAs in pulmonary sarcoidosis," European Respiratory Journal, vol. 46, supplement 59, Article ID PA3319, 2015.

[17] M. Forlenza, T. Kaiser, H. F. J. Savelkoul, and G. F. Wiegertjes, "The use of real-time quantitative PCR for the analysis of cytokine mRNA levels," Methods in Molecular Biology, vol. 820, pp. 7-23, 2012.

[18] J. Vandesompele, K. De Preter, F. Pattyn et al., "Accurate normalization of real-time quantitative RT-PCR data by geometric averaging of multiple internal control genes," Genome biology, vol. 3, no. 7, Article ID RESEARCH0034, 2002.

[19] C. L. Andersen, J. L. Jensen, and T. F. Ørntoft, "Normalization of real-time quantitative reverse transcription-PCR data: a modelbased variance estimation approach to identify genes suited for normalization, applied to bladder and colon cancer data sets," Cancer Research, vol. 64, no. 15, pp. 5245-5250, 2004.

[20] Y. Benjamini and Y. Hochberg, "Controlling the false discovery rate: a practical and powerful approach to multiple testing," Journal of the Royal Statistical Society, Series B: Methodological, vol. 57, no. 1, pp. 289-300, 1995.

[21] J. Trygg and S. Wold, "Orthogonal projections to latent structures (O-PLS)," Journal of Chemometrics, vol. 16, no. 3, pp. 119128, 2002.

[22] B. Levänen, N. R. Bhakta, P. Torregrosa Paredes et al., "Altered microRNA profiles in bronchoalveolar lavage fluid exosomes in asthmatic patients," The Journal of Allergy and Clinical Immunology, vol. 131, no. 3, pp. 894.e8-903.e8, 2013.

[23] T.-P. Lu, C.-Y. Lee, M.-H. Tsai et al., "MiRSystem: an integrated system for characterizing enriched functions and pathways of microRNA targets," PLoS ONE, vol. 7, no. 8, Article ID e42390, 2012.

[24] J. Askling, J. Grunewald, A. Eklund, G. Hillerdal, and A. Ekbom, "Increased risk for cancer following sarcoidosis," American Journal of Respiratory and Critical Care Medicine, vol. 160, no. 5, part 1, pp. 1668-1672, 1999.
[25] A. Grados, M. Ebbo, E. Bernit et al., "Sarcoidosis occurring after solid cancer: a nonfortuitous association: report of 12 cases and review of the literature," Medicine (United States), vol. 94, no. 28, article no. e928, 2015.

[26] B. D. Beutler and P. R. Cohen, "Sarcoidosis in melanoma patients: case report and literature review," Cancers, vol. 7, no. 2, pp. 1005-1021, 2015.

[27] S. Singla, T. Zhou, K. Javaid et al., "Expression profiling elucidates a molecular gene signature for pulmonary hypertension in sarcoidosis," Pulmonary Circulation, vol. 6, no. 4, pp. 465471, 2016.

[28] G. Landskron, M. De La Fuente, P. Thuwajit, C. Thuwajit, and M. A. Hermoso, "Chronic inflammation and cytokines in the tumor microenvironment," Journal of Immunology Research, vol. 2014, Article ID 149185, 19 pages, 2014.

[29] S. Khoury and N. Tran, "Circulating microRNAs: potential biomarkers for common malignancies," Biomarkers in Medicine, vol. 9, no. 2, pp. 131-151, 2015.

[30] A. P. Kiess, H. Wang, W. D. Travis, and J. Yahalom, "Sarcoid in cancer patients: clinical characteristics and associated disease status," Sarcoidosis, Vasculitis and Diffuse Lung Diseases, vol. 32, no. 3, pp. 200-207, 2015.

[31] B. Levänen, Å. M. Wheelock, A. Eklund, J. Grunewald, and M. Nord, "Increased pulmonary Wnt (wingless/integrated)signaling in patients with sarcoidosis," Respiratory Medicine, vol. 105, no. 2, pp. 282-291, 2011.

[32] A. Tzouvelekis, P. Ntolios, A. Karameris et al., "Expression of hypoxia-inducible factor (HIF)-1a-vascular endothelial growth factor (VEGF)-inhibitory growth factor (ING)-4- axis in sarcoidosis patients," BMC Research Notes, vol. 5, article 654, 2012.

[33] P. Beirne, P. Pantelidis, P. Charles et al., "Multiplex immune serum biomarker profiling in sarcoidosis and systemic sclerosis," European Respiratory Journal, vol. 34, no. 6, pp. 1376-1382, 2009.

[34] M. Yamashita, T. Mouri, M. Niisato et al., "Heterogeneous characteristics of lymphatic microvasculatures associated with pulmonary sarcoid granulomas," Annals of the American Thoracic Society, vol. 10, no. 2, pp. 90-97, 2013.

[35] R. Rastogi, W. Du, D. Ju et al., "Dysregulation of p38 and MKP-1 in response to NOD1/TLR4 stimulation in sarcoid bronchoalveolar cells," American Journal of Respiratory and Critical Care Medicine, vol. 183, no. 4, pp. 500-510, 2011.

[36] J. Xaus, N. Besalduch, M. Comalada et al., "High expression of p21Waf1 in sarcoid granulomas: a putative role for long-lasting inflammation," Journal of Leukocyte Biology, vol. 74, no. 2, pp. 295-301, 2003.

[37] J. Massagué, “TGF $\beta$ signalling in context," Nature Reviews Molecular Cell Biology, vol. 13, no. 10, pp. 616-630, 2012.

[38] G. Yang, L. Yang, W. Wang, J. Wang, J. Wang, and Z. Xu, "Discovery and validation of extracellular/circulating microRNAs during idiopathic pulmonary fibrosis disease progression," Gene, vol. 562, no. 1, pp. 138-144, 2015.

[39] A. Arakelyan, E. Kriegova, Z. Kubištova et al., "Protein levels of CC chemokine ligand (CCL)15, CCL16 and macrophage stimulating protein in patients with sarcoidosis," Clinical and Experimental Immunology, vol. 155, no. 3, pp. 457-465, 2009.

[40] N. V. Rivera, M. Ronninger, K. Shchetynsky et al., "Highdensity genetic mapping identifies new susceptibility variants in sarcoidosis phenotypes and shows genomic-driven phenotypic differences," American Journal of Respiratory and Critical Care Medicine, vol. 193, no. 9, pp. 1008-1022, 2016. 
[41] Z. Navratilova, F. Mrazek, E. Kriegova et al., "The MCP1-2518 (A to $G$ ) single nucleotide polymorphism in Czech patients with pulmonary sarcoidosis: association with Löfgren's syndrome," Sarcoidosis, Vasculitis, and Diffuse Lung Diseases: Official Journal of WASOG, vol. 24, no. 1, pp. 33-38, 2007.

[42] P. Spagnolo, H. Sato, J. Grunewald et al., "A common haplotype of the C-C chemokine receptor 2 gene and HLA-DRB1* 0301 are independent genetic risk factors for Löfgren's syndrome," Journal of Internal Medicine, vol. 264, no. 5, pp. 433-441, 2008.

[43] A. Turchinovich, T. R. Samatov, A. G. Tonevitsky, and B. Burwinkel, "Circulating miRNAs: cell-cell communication function?” Frontiers in Genetics, vol. 4, article id 119, 2013. 


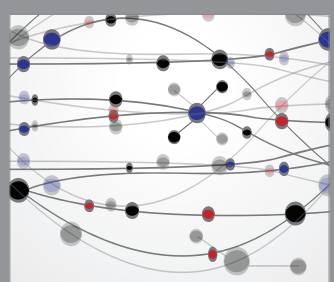

The Scientific World Journal
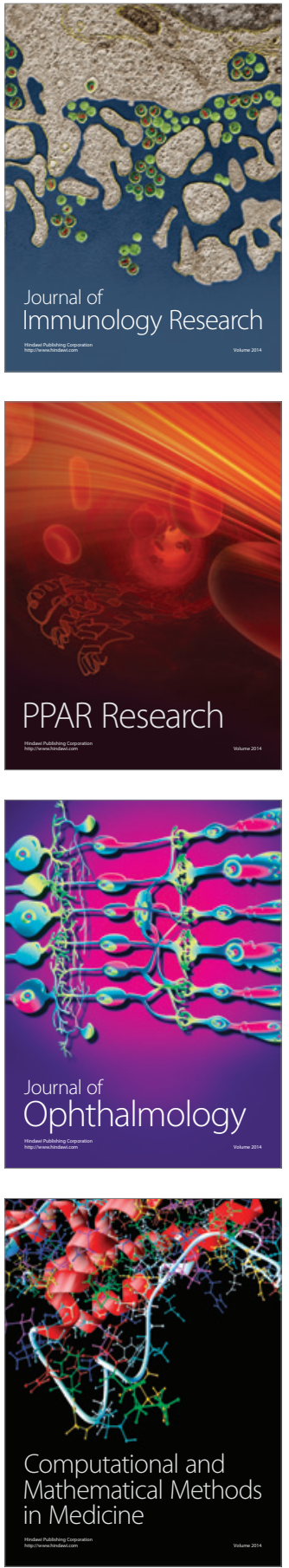

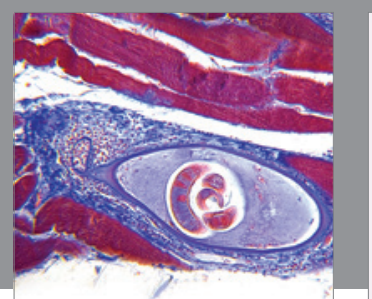

Gastroenterology Research and Practice

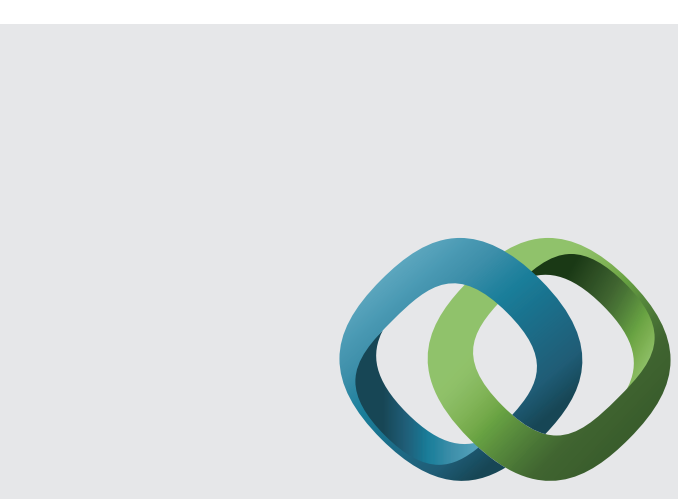

\section{Hindawi}

Submit your manuscripts at

http://www.hindawi.com
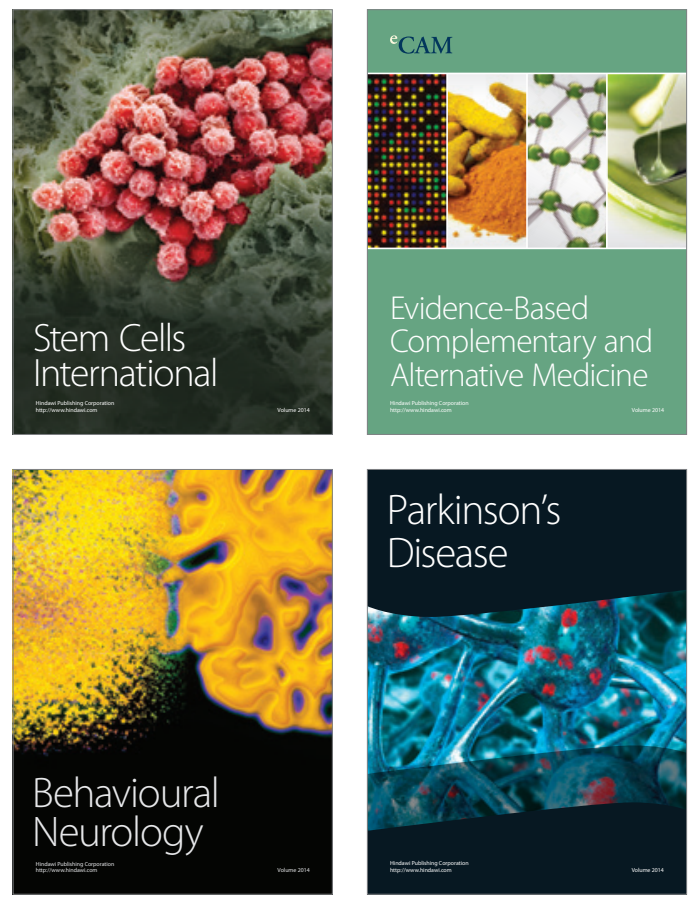
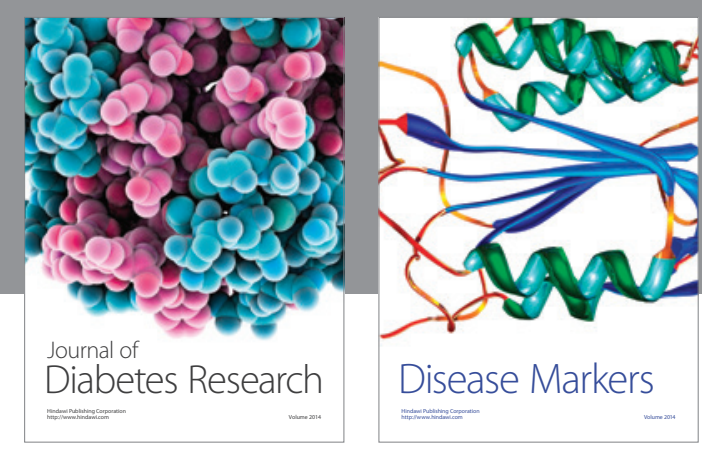

Disease Markers
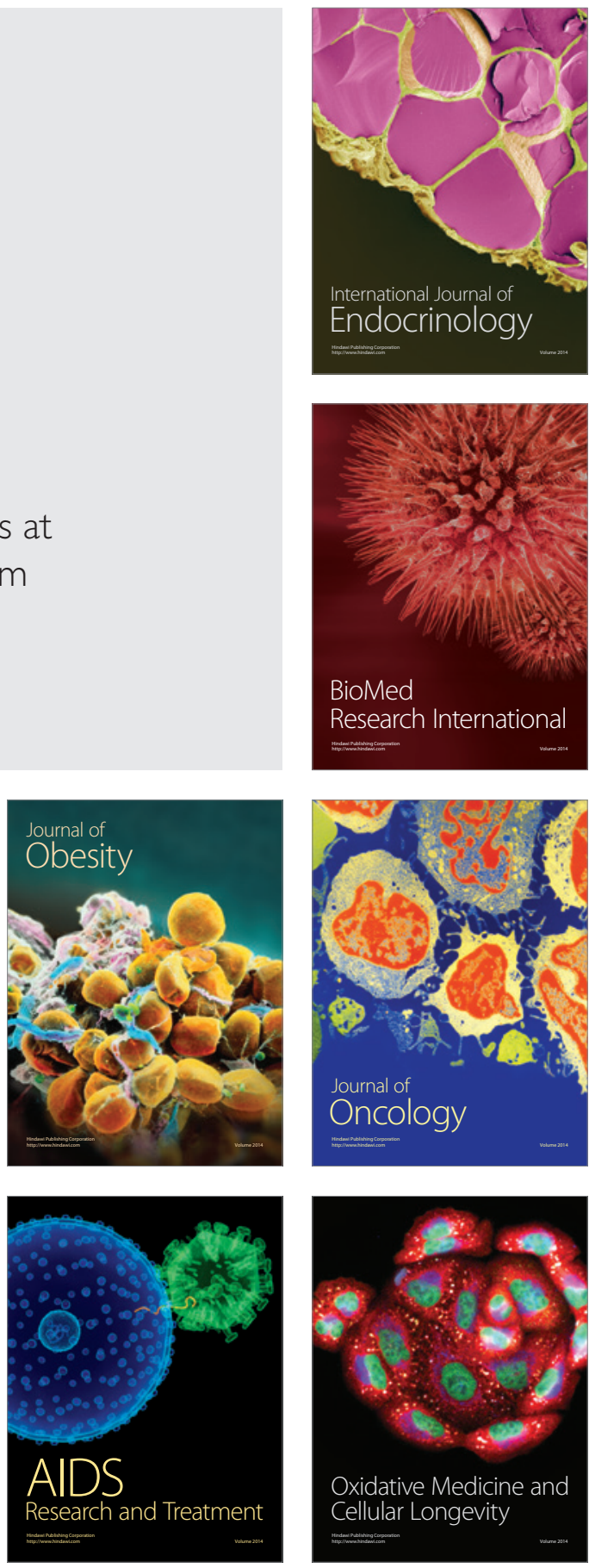